\title{
SISTEMA DE JUSTICIA PENAL JUVENIL: PRINCIPIOS RECTORES A LA LUZ DE LA CONVENCIÓN DE LOS DERECHOS DEL NIÑO
}

\section{Juvenile Criminal Justice System: Guiding Principles In The Light Of The Convention On The Rights Of The Child}

Xochithl Guadalupe RANGEL ROMERO*

\section{Sumario:}

I. Introducción II. Aproximaciones jurídicas al concepto de principio III. Principios básicos establecidos en la Convención de los Derechos del Niño IV. El sistema de justicia penal: estándares establecidos en la CDN V. Principios procesales del sistema de justicia penal juvenil VI. Conclusión

Resumen: A partir de 1989, con el nacimiento de la Convención de los Derechos del Niño (más adelante, CDN o Convención), comienza la evolución del entendimiento del adolescente en conflicto con la ley penal, quedando establecido en este instrumento normativo que se requiere la construcción de un sistema de justicia especializado para atender este paradigma de justicia novedoso. Lo anterior dio como derivación que este sistema necesariamente debe estar cimentado en principios específicos, rescatados especialmente del texto de la Convención y sobre las bases específicas que este instrumento internacional colocó al sistema de protección a la infancia. La Convención ha emitido parámetros concretos de cómo deben ser entendidos algunos principios atinentes a la materia juvenil en conflicto con la ley, que requieren ser comprendidos con la finalidad de entender -verdaderamente- el sistema de justicia especializado para adolescentes.

Palabras clave: Adolescente en conflicto con la ley, Sistema de justicia especializado, Principios en materia juvenil.

Abstract: Beginning in 1989 with the birth of the Convention on the Rights of the Child (hereafter, CRC or Convention), the evolution of the understanding of the adolescent in conflict with the criminal law begins, being established in this normative instrument that the construction of a specialized justice system is required to address this novel paradigm of justice. The foregoing led to the conclusion that this system must necessarily be

\footnotetext{
* Profesora Investigadora de Tiempo Completo en la Facultad de Derecho "Abogado Ponciano Arriaga Leíja” de la Universidad Autónoma de San Luis Potosí. Correo electrónico: xochithl.rangel@uaslp.mx; Se hace la observación al lector que parte de esta investigación pertenece al trabajo de investigación de la suscrita, para obtener el Doctorado en Ciencias Penales y Política Criminal por el Instituto Nacional de Ciencias Penales.
} 
based on specific principles, which are especially drawn from the text of the Convention and on the specific bases that this international instrument placed on the child protection system. The Convention has issued specific parameters on how certain principles relating to juvenile matters in conflict with the law should be understood, which need to be understood in order to truly understand the specialized justice system for adolescents.

Keywords. Adolescent in conflict with the law, Specialized justice system, Juvenile principles.

\section{Introducción}

Con el nacimiento de la CDN, en 1989, se encamina para la infancia novedosos sistemas de protección, lo anterior derivado de la adopción de la Doctrina de la Protección Integral de la Infancia (más adelante, DPI), que este instrumento normativo enmarca ${ }^{1}$. Lo anterior trajo como derivación que dentro de la estructura de la Convención se establecieran particularidades sobre cómo debe atenderse la temática de los adolescentes en conflicto con la ley penal. Es de recordarse que la DPI tiene como constructo principal el hecho de que el niño y la niña sean considerados como sujetos de derechos y no meros objetos de protección.

De lo que se enmarca en la CDN se ha puesto de manifiesto, dentro del hemisferio occidental, la necesidad de crearse un sistema de justicia especializado para la infancia con principios específicos que le doten de un sentido propio al quehacer de un sistema de justicia juvenil; a raíz del nacimiento de la Convención, los países comienzan una nueva (re) estructuración de sus sistemas de justicia, lo que da como atinente que el entendimiento de este novedoso sistema comience dentro de cada uno de los Estados, particularizando formas de cómo entenderlo y comprenderlo.

Con base en lo anterior, cada una de las naciones dentro de este hemisferio inicia el transitar de sus sistemas de justicia penal juvenil con la finalidad de adecuarse a lo establecido por la Convención. De lo anterior deriva el estudio de que los principios que emanan de la CDN y otros instrumentos internacionales deben tener un alcance tan amplio en la protección del derecho para los adolescentes en conflicto con la ley penal, que permita en todo caso que los Estados, sus autoridades e instituciones, mantengan un discurso elevado de interpretación, de modo que el adolescente en conflicto con la ley dentro del sistema de justicia juvenil goce de principios, valores y derechos plenos, y que las restricciones por parte de los Estados no sean adversas a todo un Sistema Interamericano de Derechos Humanos.

\section{Aproximaciones jurídicas al concepto de principio}

Una de las grandes complejidades jurídicas que a la fecha se ponderan deviene específicamente con el entendimiento de lo que debe entenderse por principio y de sus alcances. Dentro de una norma se puede acotar una gran cantidad de elementos que dotan al ser

Véase: Rangel Romero, Xochithl Guadalupe (2018), 80 preguntas sobre derechos de infancia y la justicia penal juvenil, México, editorial Flores Editor. Específicamente la sección I. 
humano de protección, sin embargo, para el caso específico, es necesario entender qué es un principio y por qué éste en lo particular tiene alcances diferentes en cuanto a la forma en que protege al ser humano.

Es de mencionarse que dentro de la literatura jurídica existe diversidad de formas de entender el principio y los alcances de éste. Siguiendo a Gustavo Zagrebelsky, los principios desempeñan un papel propiamente constitucional. [...] En las formulaciones de los principios hay poco que interpretar ${ }^{2}$. Dentro de las posiciones que establece este autor, los principios tienen la particularidad de que proporcionan criterios para tomar decisión ante situaciones concretas ${ }^{3}$.

Los principios están sujetos a ponderación al objeto de tomar una decisión específica sobre la aplicación del derecho que en ellos se constriñe, lo cual trae como resultado que un principio no esté sujeto a interpretación, pero sí a un criterio de aplicabilidad que forzosamente tiene que realizarse en el ejercicio de la dotación del derecho. Por lo cual, los principios son en esencia indispensables para una aplicación basada en una toma de decisión no mecanizada y pretenden dotar al ser humano del mejor derecho que en él se engloba.

Para precisar una aproximación jurídica al concepto de principio se podría retomar el caso de la Magistrada Margaret Marshall, Presidenta del Tribunal Supremo de Massachusetts, relacionado con la adopción o no del matrimonio homosexual en ese Estado, mismo que trasciende hacia las condiciones políticas de este país, cuando señala, que los principios ampliamente compartidos de la Constitución de su Estado, le exigían autorizar el matrimonio homosexual con independencia de lo ofensivo que pudiese parecerle a la mayoría $a^{4}$ Lo anterior puede dar cuenta de que el principio se encarga de enaltecer de forma viva lo intrínseco y que tiene un elemento objetivo dentro de las particularidades del ser humano.

El principio tiene una carga hermenéutica diferente a cualquier otra norma jurídica, dando como resultado que sea una forma específica de cómo puede interpretarse una norma, tomando siempre como referencia el núcleo esencial del cual es base. Puede afirmarse así que un principio toma en consideración la aplicación efectiva favorable al sujeto de protección.

\section{Principios básicos establecidos en la Convención de los Derechos del Niño}

Los derechos del niño y de la niña no nacen ni terminan con el texto de la CDN, lo que es pertinente en razón de que se considera que el contenido de la Convención es un estándar mínimo de reconocimiento de los derechos del niño.

Dentro del contenido de la CDN se encuentran principios generales que encaminan los derechos de la infancia en el mundo, dando como corolario que estos principios sean traspolados a los textos jurídicos de los países signatarios de la Convención, en razón de que son estos principios los que consolidan los derechos del niño no sólo dentro de la materialidad del texto de la CDN y otros instrumentos jurídicos, sino al interior de los Estados signatarios. La misma Corte ha dejado ver, dentro de su Opinión Consultiva número

\footnotetext{
Zagrebelsky, Gustavo (2002), El derecho dúctil, 4ta. Edición, Madrid, Editorial Trotta, pp. 109-110.

Ídem.

${ }^{4}$ Véase: Dworkin, Ronald (2008), La democracia posible, Principios para un nuevo debate político. España, Paidós, p. 20.
} 
$17^{5}$, que existen tres pilares fundamentales en la $\mathrm{CDN}$ que para el particular se pueden contemplar de la siguiente manera:

El primer pilar, el interés superior del niño. Siguiendo con lo que puntualiza la misma Corte Interamericana de Derechos Humanos (más adelante CIDH o Corte) dentro de su multicitada Opinión Consultiva, se específica que el interés superior del niño se funda en la dignidad misma del ser humano $0^{6}$, en el entendido de que se reconoce que es una persona y, como tal, tiene derechos, además de que estos se cimientan en la base del respeto a su dignidad. Es preciso mencionar que al presente se reconoce que debe de entenderse por este principio como la plena satisfacción de sus derechos ${ }^{7}$.

El principio del interés superior del niño se encuentra contemplado en la Convención en su artículo 3 párrafo ${ }^{8}$. De aquí se desprende que se considere como un principio básico que no puede ser alejado del texto de la Convención, ni de los instrumentos jurídicos que para tal efecto se han creado. Este principio consolida el texto de la CDN, reconociéndolo como el pilar del ejercicio de los derechos del niño, dando como consecuencia que el mismo Comité de los Derechos del Niño (más adelante, "Comité DN" o "el Comité"), viera la necesidad de especificar una Observación General únicamente para su entendimiento.

El segundo elemento, el menor de edad como sujeto de derechos. Uno de los postulados más importantes que implementa la DPI al texto de la Convención es el reconocimiento del niño y la niña como sujeto de derechos, dando un revés a las especificidades que fueron contempladas en la Doctrina de la Situación Irregular. Retomando lo que señala Cillero Bruñol: Otra característica fundamental del enfoque de derechos humanos aplicado a la infancia, es construir una nueva concepción del niño y sus relaciones con la familia, la sociedad y el Estado. [...] se basa en el reconocimiento expreso del niño como sujeto de derechos, en oposición a la idea predominante de niño definido a partir de su incapacidad jurídica ${ }^{9}$. De lo anterior, se reconoce que el niño adquiere derechos por el solo hecho de ser persona, dando como derivación que se deje atrás una imagen de niño protegido por su incapacidad.

${ }^{5}$ La cita de la CIDH en su párrafo 15 señala expresamente: el interés superior del niño, entendido como la premisa bajo la cual se debe interpretar, integrar y aplicar la normativa de la niñez y la adolescencia, y que constituye, por ello, un límite a la discrecionalidad de las autoridades en la adopción de decisiones relacionadas con los niños; el menor de edad como sujeto de derecho, de manera que se reconocen a éste tanto los derechos humanos básicos como los que sean propios de su condición de niño; y el ejercicio de los derechos fundamentales y su vínculo a la autoridad parental: siendo que la autoridad parental tiene como único fin procurar al niño la protección y los cuidados indispensables para garantizar su desarrollo integral, constituye una responsabilidad y un derecho para los padres, pero también un derecho fundamental para los niños a ser protegidos y orientados hasta alcanzar su plena autonomía. Por ello, el ejercicio de autoridad debe disminuir conforme avanza la edad del niño.

${ }^{6}$ Confrontar en: Corte Interamericana de Derechos Humanos, Opinión Consultiva número 17, párrafos 56-61.

7 Cillero Bruñol, Miguel (1999), Justicia y Derechos del Niño, número 1, El interés superior del niño en el marco de la Convención Internacional sobre los derechos del niño, Chile, UNICEF, p. 54.

8 En todas las medidas concernientes a los niños que tomen las instituciones públicas o privadas de bienestar social, los tribunales, las autoridades administrativas o los órganos legislativos, una consideración primordial a que se atenderá será el interés superior del niño.

9 Cillero Bruñol, Miguel (s.a), Infancia, Autonomía y Derechos: una cuestión de principios. [en línea] disponible en: http://www.iin.oea.org/Infancia_autonomia_derechos.pdf, p. 4. 
Y por último, el ejercicio de los derechos fundamentales y su vínculo a la autoridad parental. El texto de la Convención abre el entendimiento hacia las necesidades del niño, dando como derivación que el niño en alcance de su autonomía logre plenamente materializar todos y cada uno de sus derechos únicamente con el paso del tiempo y atendiendo a su misma evolución de desarrollo. Esto traerá como consecuencia que los padres, la familia y el mismo Estado, tengan la obligación de proteger al niño y a la niña, en relación con el derecho que dejan de ejercer por su condición evolutiva propia, sin que esto sea una constante, por lo que se puede señalar que los derechos del niño se materializan de forma estratificada en relación al mismo desarrollo evolutivo del niño.

Una vez planteado que lo que establece la CIDH son los pilares básicos de la CDN, se constituye que dentro del texto de la Convención están consolidados cuatro principios esenciales, todos fluctuando no sólo para el entendimiento de los derechos de los niños, sino para el reconocimiento de estos dentro de los diversos instrumentos jurídicos que para la infancia se han redactado.

Para el entendimiento del texto de la Convención es pertinente abocarnos a cuatro principios básicos que son torales para la comprensión de los derechos de la infancia, a saber: 1) El principio de no discriminación, 2) El principio del Interés Superior del Niño, 3) El principio de participación y, 4) El principio del derecho a la vida, a la supervivencia y al desarrollo. De manera específica, estos cuatro principios consolidan el estudio de los derechos de la infancia, en razón de que es a partir de estos que el contenido del texto de la Convención se puede materializar poniendo énfasis en lo señalado por Herrera Zamora, sin alguno de estos pilares sería como ver una mesa sin alguna de sus patas ${ }^{10}$. Ciertamente, dentro de la estructura del texto de la $\mathrm{CDN}$, estos principios engloban no sólo el entendimiento de los derechos del niño como tales, sino el alcance de estos al interior de las naciones signatarias de la Convención.

Por una cuestión de método obligada es preciso detenernos en el estudio de los principios ofrecidos por el texto de la CDN, con la única intención de encaminar el objeto de investigación que aquí interesa, dando paso a señalar:

El principio de no discriminación. Este principio se encuentra consagrado dentro del texto de la $\mathrm{CDN}$ en su numeral $2^{11}$. De la lectura íntegra de este artículo se desprende que este principio se proyecta en dos ámbitos: la no discriminación por cualidades del niño o de la niña, y la no discriminación por cualidades de los padres ${ }^{12}$.

Grosso modo, el entendimiento del principio de no discriminación encuentra sustento en los diversos razonamientos que ha expresado el mismo Comité DN, a través de la diversidad de observaciones generales que éste emite, dando como derivación que el

\footnotetext{
${ }^{10}$ Herrera Zamora, Annie (2011), El impacto de la Doctrina de la Protección Integral (DPI) de los derechos de la infancia en los derechos económicos sociales y culturales (DESC) de la infancia en el DF. Tesis de Maestría. Sede Académica de México, Facultad Latinoamericana en Ciencias Sociales, p. 22.

${ }^{11}$ Los Estados partes respetarán los derechos enunciados en la presente Convención y asegurarán su aplicación a cada niño sujeto a su jurisdicción, sin distinción alguna, independientemente de la raza, el color, el sexo, el idioma, la religión, la opinión política o de otra índole, el origen nacional, étnico o social, la posición económica, los impedimentos físicos, el nacimiento o cualquier otra condición del niño, de sus padres o de sus representantes legales.

${ }^{12}$ García Chavarría, Ana Belem (2012), La Convención de los derechos del niño, fascículo 8, México, Comisión Nacional de Derechos Humanos, p. 23.
} 
contenido del texto de la Convención tenga forzosamente que ser enunciativo más no limitativo del contenido jurídico que éste expresa. El Comité ha dejado ver que es necesario vigorizar los esfuerzos por dejar atrás la discriminación que impera para los niños. La no discriminación es mucho más de lo expresado por el numeral 2 de la CDN, así lo manifiesta el Comité dentro de su Observación General número 4, denominada "La salud y el desarrollo de los adolescentes en el contexto de la Convención de los Derechos del Niño": Debe añadirse también la orientación sexual y el estado de salud del niño (con la inclusión del VIH/SIDA y la salud mental) ${ }^{13}$. Lo anterior visualiza que el principio de no discriminación sea visto de manera holística; una de las grandes preocupaciones que manifiesta el Comité va dirigida al duro trato al cual son sujetos los niños, pues la discriminación también consiste: en una peor nutrición, en una atención y cuidado insuficientes, en menores oportunidades de juego, aprendizaje y educación, o en la inhibición de la libre expresión de los sentimientos y opiniones ${ }^{14}$.

El principio del interés superior del niño. La consagración de este principio se materializa en el artículo 3 párrafo I de la CDN. Si bien los cuatro principios que evoca la Convención son importantes, no lo es menos el interés superior del niño, que se consagra como un principio toral de materialización de los derechos del niño. El principio del interés superior del niño se encuentra vigente desde la DDN y se consolida en la CDN, como ha sido expresado por el mismo Comité DN dentro de su Observación General número 14, denominada, "Sobre el derecho del niño a que su interés superior sea una consideración primordial": un derecho sustantivo, un principio jurídico interpretativo fundamental y una norma de procedimiento ${ }^{15}$.

Se consolida entonces que el interés superior del niño impone una obligación de aplicación a los Estados signatarios, donde la consideración de su cuidado no queda a una

${ }^{13}$ Confrontar en: Observación General No. 4 (2003), La salud y el desarrollo de los adolescentes en el contexto de la Convención de los Derechos del Niño, Comité de los Derechos del Niño, CRC/GC/2003/4. Párrafo 6.

${ }^{14}$ Confrontar en: Observación General No. 7 (2005), Realización de los derechos del niño en la primera infancia, Comité de los Derechos del Niño, CRC/GC/2005/7. Párrafo 12, inciso b).

${ }^{15}$ a) Un derecho sustantivo: el derecho del niño a que su interés superior sea una consideración primordial que se evalúe y tenga en cuenta al sopesar distintos intereses para tomar una decisión sobre una cuestión debatida, y la garantía de que ese derecho se pondrá en práctica siempre que se tenga que adoptar una decisión que afecte a un niño, a un grupo de niños concreto o genérico o a los niños en general. El artículo 3 , párrafo 1, establece una obligación intrínseca para los Estados, es de aplicación directa (aplicabilidad inmediata) y puede invocarse ante los tribunales.

b) Un principio jurídico interpretativo fundamental: si una disposición jurídica admite más de una interpretación, se elegirá la interpretación que satisfaga de manera más efectiva el interés superior del niño. Los derechos consagrados en la Convención y sus Protocolos facultativos establecen el marco interpretativo.

c) Una norma de procedimiento: siempre que se tenga que tomar una decisión que afecte a un niño en concreto, a un grupo de niños concreto o a los niños en general, el proceso de adopción de decisiones deberá incluir una estimación de las posibles repercusiones (positivas o negativas) de la decisión en el niño o los niños interesados. La evaluación y determinación del interés superior del niño requieren garantías procesales. Además, la justificación de las decisiones debe dejar patente que se ha tenido en cuenta explícitamente ese derecho. En este sentido, los Estados partes deberán explicar cómo se ha respetado este derecho en la decisión, es decir, qué se ha considerado que atendía al interés superior del niño, en qué criterios se ha basado la decisión y cómo se han ponderado los intereses del niño frente a otras consideraciones, ya se trate de cuestiones normativas generales o de casos concretos. 
discrecionalidad de éste, sino que es forzosa su diligencia ponderando siempre lo más favorable para el niño.

El principio de participación. A este principio también se le conoce como principio a ser escuchado y a expresar su opinión. Se encuentra puntualizado en el numeral $12.1^{16} \mathrm{y}$ $12.2^{17}$ de la Convención.

Como lo ha dejado ver el Comité dentro de la Observación General número 12 denominada, "El derecho del niño a ser escuchado", que busca ampliar el contenido del artículo 12 de la $\mathrm{CDN}^{18}$ : todo aquel niño que pueda formarse un criterio propio, tiene derecho a expresar su opinión, y que ésta sea tomada en consideración al momento de resolver cuando dentro de un procedimiento el niño se vea involucrado, asimismo se consagra el derecho a ser escuchado en todo proceso ya sea administrativo y/o judicial que le afecte. El derecho a ser escuchado y a participar es un derecho que puede ser aplicado a un grupo o de manera individual. Como se ha precisado también por parte del mismo Comité DN, el niño tiene derecho a no ejercer ese derecho ${ }^{19}$, dando como consecuencia que el principio de ser escuchado y participación sea dúctil.

El principio del derecho a la vida, a la supervivencia y al desarrollo. Este principio se reconoce expresamente en los artículos $6.1^{20}$ y $6.2^{21}$ de la Convención.

La misma Corte Interamericana, dentro de su Opinión Consultiva número 17, se ha ponderado sobre este principio, con base en lo siguiente:

Que el respeto del derecho a la vida, en relación con los niños, abarca no sólo las prohibiciones, entre ellas, la de la privación arbitraria, establecidas en el artículo 4 de la Convención Americana sobre Derechos Humanos, sino que comprende también la obligación de adoptar las medidas necesarias para que la existencia de los niños se desarrolle en condiciones dignas.

Que la verdadera y plena protección de los niños significa que estos puedan disfrutar ampliamente de todos sus derechos, entre ellos los económicos, sociales y culturales, que les asignan diversos instrumentos internacionales. Los Estados Partes en los tratados internacionales de derechos humanos tienen la obligación de adoptar medidas positivas para asegurar la protección de todos los derechos del niño ${ }^{22}$.

Los cuatro principios aquí señalados se convierten en principios torales de la CDN, dando como derivación que sea partir de estos que los derechos para la niñez tengan que ser visualizados, reconocidos, materializados y protegidos por parte de los Estados.

\footnotetext{
${ }^{16}$ Los Estados Partes garantizarán que esté en condiciones de formarse un juicio propio el derecho de expresar su opinión libremente en todos los asuntos que afectan al niño, teniéndose debidamente en cuenta las opiniones del niño, en función de la edad y madurez del niño.

${ }^{17}$ Con tal fin, se dará en particular al niño oportunidad de ser escuchado en todo procedimiento judicial o administrativo que afecte al niño, ya sea directamente o por medio de un representante o de un órgano apropiado, en consonancia con las normas de procedimientos de la ley nacional.

${ }^{18}$ Véase: Observación General No. 12 (2009), El derecho del niño a ser escuchado, Comité de los Derechos del Niño, CRC/GC/12/2009. Párrafo 1.

${ }^{19}$ Ídem, Párrafo 16.

${ }^{20}$ Los Estados Partes reconocen que todo niño tiene el derecho intrínseco a la vida.

${ }^{21}$ Los Estados Partes garantizarán en la máxima medida de lo posible la supervivencia y el desarrollo del niño.

${ }^{22}$ Corte Interamericana de Derechos Humanos, op. cit, nota 6, Párrafo 137.
} 


\section{El sistema de justicia penal: estándares establecidos en la CDN}

Los diversos instrumentos internacionales que reconocen derechos de la infancia en el tópico de la justicia penal buscan encaminar a los Estados Partes en la actuación que estos deben de encauzar para los niños en conflicto con la ley penal. Esto con la finalidad de que las disposiciones que se establecen en los instrumentos internacionales se logren materializar plenamente dentro de las naciones que han ratificado los diversos documentos internacionales, aceptándolos de buena fe.

Es pertinente retomar como instrumento base a la misma Convención; uno de los parámetros más importantes que se rescatan del texto de la $\mathrm{CDN}$, además del reconocimiento pleno de que el niño es sujeto de derechos, se erige en el principio del interés superior del niño, como una insignia que deben seguir los Estados para el cumplimiento de las obligaciones contraídas por estos. Por lo tanto, el principio del interés superior del niño es un cimiento, dentro del tópico de los niños en conflicto con la justicia, de forzosa aplicación.

Ahora bien, para el tema de los niños en conflicto con la ley penal, dentro del texto de la Convención se encuentran dos numerales que consolidan no sólo pautas orientadoras al tópico en comento, sino que son un verdadero parámetro de aplicación, mismo que los Estados Partes deben necesariamente considerar.

Los numerales que se encuadran en el tópico de los niños en conflicto con la ley penal son los artículos 37 y 40 de la CDN, mismos que consolidan la medida de aplicación para los niños en conflicto con la ley penal, y se armonizan al contenido que se encuentra regulado en otros instrumentos internacionales.

En primera instancia, será pertinente establecer y analizar el texto de la Convención con la única encomienda de especificar cómo la CDN visualiza el tópico del sistema de justicia que se aplica para los niños en conflicto con la ley penal. De lo anterior se desprende que el artículo 37 de la Convención, establece a la letra lo siguiente:

Los Estados Partes velarán por que:

a) Ningún niño sea sometido a torturas ni a otros tratos o penas crueles, inhumanos o degradantes. No se impondrá la pena capital ni la de prisión perpetua sin posibilidad de excarcelación por delitos cometidos por menores de 18 años de edad;

b) Ningún niño sea privado de su libertad ilegal o arbitrariamente. La detención, el encarcelamiento o la prisión de un niño se llevará a cabo de conformidad con la ley y se utilizará tan sólo como medida de último recurso y durante el periodo más breve que proceda;

c) Todo niño privado de libertad sea tratado con la humanidad y el respeto que merece la dignidad inherente a la persona humana, y de manera que se tengan en cuenta las necesidades de las personas de su edad. En particular, todo niño privado de libertad estará separado de los adultos, a menos que ello se considere contrario al interés superior del niño, y tendrá derecho a mantener contacto con su familia por medio de correspondencia y de visitas, salvo en circunstancias excepcionales;

d) Todo niño privado de su libertad tendrá derecho a un pronto acceso a la asistencia jurídica y otra asistencia adecuada, así como derecho a impugnar la legalidad de la privación de su libertad ante un tribunal u otra autoridad competente, independiente e imparcial y a una pronta decisión sobre dicha acción. 
Es pertinente retomar y resaltar los puntos torales de este numeral con el propósito de construir el camino que visualiza la CDN para el particular. Por lo anteriormente dicho, se puede desprender del artículo 37 -para el tópico en específico que interesa- lo siguiente:

1. Principio de Dignidad Humana que debe ser respetado al niño en conflicto con la justicia

2. Al niño no puede imponérsele pena de muerte ni prisión perpetua por los delitos cometidos

3. El niño no puede ser privado de su libertad de manera ilegal o arbitraria

4. El encarcelamiento o prisión de un niño siempre tiene que estar de conformidad con la ley, y aplicado como ultima ratio durante el tiempo más breve que proceda

5. Aquel niño que es privado de su libertad deberá ser tratado siempre respetando su dignidad humana

6. Todo niño que es privado de la libertad deberá estar separado de los adultos, manifestando la excepción contemplada en la CDN

7. Todo niño privado de libertad tiene derecho a mantener correspondencia y visitas, manifestando la excepción contemplada en la Convención

8. Todo niño privado de libertad tendrá derecho a una pronta asistencia jurídica y otra asistencia adecuada, y

9. Todo niño privado de libertad tendrá derecho a impugnar ante un Tribunal la ilegalidad sobre la privación de su libertad

Estos nueve puntos expresados son especificidades propias que se rescatan del texto de la Convención, elegidos mediante una interpretación literal del contenido del artículo con la premisa básica de que estos enunciados responden a las necesidades específicas de este numeral, y expresan la forma en la cual los Estados deben de guiar el tópico de la justicia juvenil dentro de sus Estados.

Ahora bien, es preciso también señalar el contenido del artículo 40 de la CDN, con el objeto de visualizar qué alcance pondera la Convención, para el tópico de los niños en conflicto con la ley penal:

Articulo 40

1. Los Estados Partes reconocen el derecho de todo niño de quien se alegue que ha infringido las leyes penales o a quien se acuse o declare culpable de haber infringido esas leyes a ser tratado de manera acorde con el fomento de su sentido de la dignidad y el valor, que fortalezca el respeto del niño por los derechos humanos y las libertades fundamentales de terceros y en la que se tengan en cuenta la edad del niño y la importancia de promover la reintegración del niño y de que éste asuma una función constructiva en la sociedad.

2. Con este fin, y habida cuenta de las disposiciones pertinentes de los instrumentos internacionales, los Estados Partes garantizarán, en particular:

a) Que no se alegue que ningún niño ha infringido las leyes penales, ni se acuse o declare culpable a ningún niño de haber infringido esas leyes, por actos u omi- 
siones que no estaban prohibidos por las leyes nacionales o internacionales en el momento en que se cometieron;

b) Que a todo niño del que se alegue que ha infringido las leyes penales o a quien se acuse de haber infringido esas leyes se le garantice, por lo menos, lo siguiente:

i) Que se lo presumirá inocente mientras no se pruebe su culpabilidad conforme a la ley;

ii) Que será informado sin demora y directamente o, cuando sea procedente, por intermedio de sus padres o sus representantes legales, de los cargos que pesan contra él y que dispondrá de asistencia jurídica u otra asistencia apropiada en la preparación y presentación de su defensa;

iii) Que la causa será dirimida sin demora por una autoridad u órgano judicial competente, independiente e imparcial en una audiencia equitativa conforme a la ley, en presencia de un asesor jurídico u otro tipo de asesor adecuado y, a menos que se considerare que ello fuere contrario al interés superior del niño, teniendo en cuenta en particular su edad o situación y a sus padres o representantes legales;

iv) Que no será obligado a prestar testimonio o a declararse culpable, que podrá interrogar o hacer que se interrogue a testigos de cargo y obtener la participación y el interrogatorio de testigos de descargo en condiciones de igualdad;

v) Si se considerare que ha infringido, en efecto, las leyes penales, que esta decisión y toda medida impuesta a consecuencia de ella, serán sometidas a una autoridad u órgano judicial superior competente, independiente e imparcial, conforme a la ley;

vi) Que el niño contará con la asistencia gratuita de un intérprete si no comprende o no habla el idioma utilizado;

vii) Que se respetará plenamente su vida privada en todas las fases del procedimiento.

3. Los Estados Partes tomarán todas las medidas apropiadas para promover el establecimiento de leyes, procedimientos, autoridades e instituciones especificos para los niños de quienes se alegue que han infringido las leyes penales o a quienes se acuse o declare culpables de haber infringido esas leyes, y en particular:

a) El establecimiento de una edad mínima antes de la cual se presumirá que los niños no tienen capacidad para infringir las leyes penales;

b) Siempre que sea apropiado y deseable, la adopción de medidas para tratar a esos niños sin recurrir a procedimientos judiciales, en el entendimiento de que se respetarán plenamente los derechos humanos y las garantías legales.

4. Se dispondrá de diversas medidas, tales como el cuidado, las órdenes de orientación y supervisión, el asesoramiento, la libertad vigilada, la colocación en hogares de guarda, los programas de enseñanza y formación profesional, asi como otras posibilidades alternativas a la internación en instituciones, para asegurar que los niños sean tratados de manera apropiada para su bienestar y que guarde proporción tanto con sus circunstancias como con la infracción. 
De la misma manera, es pertinente retomar y resaltar los puntos torales de este numeral con el único propósito de identificar los aspectos más relevantes de este artículo, y de aquí partir a la explicación efectiva de los principios procesales más relevantes en la materia del sistema de justicia penal juvenil, tomando para su explicación y enunciación un análisis minucioso al contenido del articulado con la única finalidad de construir el camino que visualiza la CDN. Por lo anteriormente dicho, se puede desprender del artículo 40 de la Convención, para el tópico en específico que interesa, los siguientes puntos:

1. Principio de Dignidad Humana que debe ser respetado al niño en conflicto con la ley penal

2. Principio de nullum crimen sine lege

3. Principio de presunción de inocencia

4. El niño debe de conocer en todo momento la acusación contra él

5. Principio de defensa en todo el procedimiento

6. Todo niño tiene derecho a un juicio bajo un sistema de audiencias ante un tribunal competente, justo e imparcial

7. Principio de no autoincriminación (nemo tenetur)

8. Todo niño tiene derecho a interrogar o hacer que interroguen a testigos de cargo

9. Todo niño tiene derecho a participar e interrogar en testigos de descargo

10. Todo niño al que se le ha comprobado haber infringido la ley penal tiene derecho a que las medidas que se apliquen para éste sean sometidas a una autoridad superior

11. Todo niño contará con asistencia gratuita de un intérprete si no conoce o habla el idioma

12. Respeto pleno a su vida privada durante el procedimiento

13. Todo niño que ha infringido la ley penal tiene derecho a leyes, procedimiento, autoridades e instituciones especializadas

14. Fijación de una edad de responsabilidad penal juvenil establecida

15. En la medida que sea posible no utilizar procedimientos judiciales en contra de los niños en conflicto con la ley penal

16. Todo niño que ha infringido la ley penal tiene derecho a un catálogo de medidas que puede ser utilizados para su reintegración social y familiar

Estos dieciséis puntos expresados, identificados previamente en el texto de la Convención, expresan la forma en la cual los Estados deben de guiar el tópico de la justicia juvenil dentro de sus Estados.

Expresamente, cada numeral encamina estándares mínimos que deben de ser traspolados al niño en conflicto con la ley penal. Ahora bien, atento a lo anterior, es procedente explicar cada uno de estos estándares consagrados, con la finalidad de encaminar el modelo que debe ser aplicado desde los instrumentos internacionales para el tópico de los niños en conflicto con la ley penal. 
El texto de la Convención se ha convertido en un parteaguas del reconocimiento de los derechos humanos de los niños en el orbe mundial, lo que hace alusión a que, dentro de las especificidades contenidas en la CDN, se encamina hacia un modelo (s) que orienta (n) la (s) forma (s) en la cual los Estados deben de materializar las diversas disposiciones que el texto de la Convención expresa.

Para el tópico que nos ocupa, es decir, el tema de los niños y niñas en conflicto con la ley penal, los artículos 37 y 40 de la CDN establecen un panorama encaminado a la administración de la justicia juvenil, que deben de expresar los Estados Parte de la Convención, basando lo anterior en los principios que se desprende de estos numerales.

\section{Principios procesales del sistema de justicia penal juvenil}

Es preciso entonces estudiar los principios procesales rescatados del numeral 40 de la CDN, con la única intención de visualizar el modelo de administración de justicia que impera desde el texto de la CDN, procurando armonizarlo con las disposiciones que establecen otros instrumentos internacionales.

En el tópico de la administración de justicia se tienen cuatro principios que son cimiento natural, y que con base en estos se circula una armonía de derechos: el interés superior del niño, el principio de no discriminación, el principio de derecho a la vida, a la supervivencia y al desarrollo, y el principio de participación, mismos que ya fueron retomados en líneas anteriores y que son el eje de los principios procesales que en estos momentos se encaminan.

Ahora bien, de lo anterior se colige que es necesario estudiar los principios procesales que se desarrollan en el tópico de la administración de la justicia juvenil, con la única finalidad de entender la forma en la cual se encamina este modelo de protección de los derechos de los niños en conflicto con la ley penal. Como lo establece la Convención, en el derecho procesal que ésta orienta, se desprenden los siguientes principios:

\section{El principio de nullum crimen sine lege}

Este principio se encuentra consagrado en el numeral 40.2.a. de la Convención, donde refiere: a) Que no se alegue que ningún niño ha infringido las leyes penales, ni se acuse o declare culpable a ningún niño de haber infringido esas leyes, por actos $u$ omisiones que no estaban prohibidos por las leyes nacionales o internacionales en el momento en que se cometieron; es preciso comentar el hecho de que dentro del texto de la Opinión Consultiva que ha emitido la CIDH se pondera bajo un principio de legalidad establecido, es decir, que la aplicación de una ley a un niño en conflicto con la ley penal debe estar previamente establecida, bajo parámetros y mecanismos conocidos ${ }^{23}$.

Este principio se encuentra recogido dentro de otros instrumentos, por ejemplo, en las Reglas de Beijín (más adelante, RB), específicamente en la regla 2.324; asimismo,

\footnotetext{
${ }^{23}$ Texto de la OP-17 dentro del párrafo 108 puntualiza: cuando aquellos o estos realizan hechos previstos como punibles en las leyes penales. Es preciso, pues, que la conducta que motiva la intervención estatal sea plenamente típica.

${ }^{24}$ La regla 2.3 dicta: que en cada jurisdicción nacional se procurará promulgar un conjunto de leyes, normas y disposiciones aplicables especificamente a los jóvenes delincuentes, así como a los órganos e instituciones encargados de las funciones de administración de la justicia de menores.
} 
en las Directrices de las Naciones Unidas para la Prevención de la Delincuencia Juvenil (más adelante, "Directrices de Riad" o "DR"), en su regla $56^{25}$.

Como ha sido establecido por la doctrina, este principio implica no sólo que la conducta que se le imputa a un niño en conflicto con la ley se encuentre prevista en una ley, sino que esta ley haya reunido los mecanismos de vigencia propios, antes de la comisión de la conducta, bajo rasgos de certeza, claridad en su texto, y la especificidad de la conducta que pretende regular. Por lo tanto, la obediencia a este principio no sólo implica que deba de aplicarse una ley, sino que la diligencia de una ley a una conducta propicia que esta ley y la conducta que ésta regula, se encuentren descritas con anterioridad al hecho cometido, y que esta ley emane bajo un mecanismo legal específico.

\section{El principio de presunción de inocencia}

Este principio se encuentra consagrado dentro del numeral 40.2.b.i de la Convención, donde expresamente consagra que: i) Que se lo presumirá inocente mientras no se pruebe su culpabilidad conforme a la ley; el principio de presunción de inocencia, derivado de lo anterior, opera en favor del niño en conflicto con la ley penal hasta en tanto no se demuestre una responsabilidad plena de una conducta típica, antijurídica y culpable, descrita en una ley con anterioridad a la conducta que fue cometida.

Es preciso hacer notar que otros instrumentos internacionales han rescatado que el principio de presunción de inocencia debe operar en favor del niño en conflicto con la ley penal. Entre estos encontramos las RB, dentro de su regla $7.1^{26}$, misma que especifica que el principio de presunción de inocencia es una garantía procesal básica en el derecho de menores. Es menester puntualizar que el mismo Comité ha descrito dentro de su Observación General número 10, que si el niño en conflicto con la ley penal que es acusado se comportara de forma sospechosa, no bastase lo anterior para presumir con ello que éste es culpable de la conducta ${ }^{27}$.

El principio de presunción de inocencia, que opera desde instrumentos internacionales a favor del niño en conflicto con la ley penal, ha sido inclusive mencionado en criterios de sentencia por la misma Corte y, por lo tanto, obliga a toda autoridad en este hemisferio a respetarlo, mientras no se establezca una responsabilidad penal plena bajo un mecanismo de comprobación, dentro un sistema especializado de justicia juvenil que tenga que ser aplicado ${ }^{28}$.

El principio de presunción de inocencia es un principio dúctil que se complementa con otros principios, así lo ha dejado ver la misma CIDH dentro de la sentencia caso "Instituto de Reeducación del Menor" Vs Paraguay ${ }^{29}$.

\footnotetext{
${ }^{25}$ La regla 56 señala: A fin de impedir que prosiga la estigmatización, [...] de los jóvenes, deberán promulgarse leyes que garanticen que ningún acto sea considerado delito ni sea sancionado cuando lo comete un adulto se considere delito ni sea objeto de sanción cuando es cometido por un joven.

${ }^{26}$ La regla 7.1 señala: En todas las etapas del proceso se respetarán las garantías procesales básicas tales como la presunción de inocencia.

${ }^{27}$ Véase: Observación General número 10 del Comité de los Derechos del Niño: Específicamente el párrafo 42.

${ }^{28}$ Véase: La sentencia de la Corte Interamericana de Derechos Humanos, caso Bulacio Vs Argentina, sentencia de 18 de septiembre de 2003 (Fondo, Reparaciones y Costas), específicamente el párrafo 129.

${ }^{29}$ Vid: La sentencia de la Corte Interamericana de Derechos Humanos, caso "Instituto de Reeducación del Menor" Vs Paraguay, sentencia de 2 de septiembre de 2004 (Excepciones preliminares, Fondo, Reparaciones y Costas), específicamente el párrafo 228.
} 


\section{El derecho a ser informado y a la asistencia jurídica}

Este derecho se encuentra consagrado dentro de las disposiciones que establece el numeral 40.2.b.ii de la CDN, donde señala: ii) Que será informado sin demora y directamente $o$, cuando sea procedente, por intermedio de sus padres o sus representantes legales, de los cargos que pesan contra él y que dispondrá de asistencia jurídica u otra asistencia apropiada en la preparación y presentación de su defensa; es necesario hacer la acotación que dentro de las disposiciones que se establecen dentro de las RB en su regla $15.1^{30}$, se acota que el menor tiene derecho no sólo a mantener asistencia jurídica como tal, sino a solicitarle al Estado ésta.

Asimismo, el Comité, dentro de la Observación General número 10, ha puntualizado que la interpretación que se le debe dar a este derecho, consagrado en la Convención, hace alusión "a lo antes posible". De lo cual se infiere que el niño en conflicto con la justicia, debe ser informado lo antes posible de los cargos que operan en su contra. El derecho que se consagra a favor del niño tiene relación directa con toda información que pueda perjudicarle dentro de un proceso, así como con la información que pueda beneficiarle.

El Estado no sólo tiene la obligación de informar al menor, sino que esta información tiene que ser expresada en un lenguaje que el niño pueda comprender. Ahora bien, es de comentarse que la asistencia jurídica que se le debe brindar al niño tiene que ser apropiada.

El derecho a ser informado y a la asistencia jurídica se ve materializado dentro diversos fallos que se han puntualizado por parte de la CIDH, específicamente, en las sentencias a los casos: Bulacio Vs. Argentina, González y otras Vs. México y el caso de los Hermanos Gómez Paquiyauri Vs. Perú. La Corte ha ponderado que el derecho a ser informado y a la asistencia jurídica, en su momento, fue violentado, ello en razón de que los Estados recurridos fueron omisos en brindar un derecho a ser informado y a la asistencia jurídica de manera eficiente, tanto para los niños, cuanto para los familiares de estos.

\section{El derecho a ser juzgado sin demora ante un tribunal competente, justo e imparcial (Juez natural)}

Este derecho se encuentra consagrado dentro de las disposiciones que se establecen en el artículo 40.2.b.iii de la Convención, donde dice: iii) Que la causa será dirimida sin demora por una autoridad u órgano judicial competente, independiente e imparcial en una audiencia equitativa conforme a la ley, en presencia de un asesor jurídico u otro tipo de asesor adecuado y, a menos que se considerare que ello fuere contrario al interés superior del niño, teniendo en cuenta en particular su edad o situación y a sus padres o representantes legales; es preciso hacer la mención que dentro de las RB en su numeral $14.1^{31}$, se señala que debe existir una autoridad competente que debe de encaminar el proceso del niño en conflicto con la ley penal.

\footnotetext{
${ }^{30}$ La regla 15.1: El menor tendrá derecho a hacerse representar por un asesor jurídico durante todo el proceso o a solicitar asesoría jurídica gratuita cuando esté prevista la prestación de ayuda en el país.

${ }^{31}$ Todo menor delincuente cuyo caso no sea objeto de remisión (con arreglo a la regla 11) será puesto a disposición de la autoridad competente (corte, tribunal, junta, consejo, etc.), que decidirá con arreglo a los principios de un juicio imparcial y equitativo.
} 
La misma Corte, dentro de su Opinión Consultiva 1732, hace mención que debe de existir un juez natural, es decir, un órgano judicial competente, independiente e imparcial, que imparta justicia dentro del proceso penal juvenil que se actualiza para un niño en conflicto con la justicia.

Ahora bien, la misma CIDH, dentro de diversos fallos ha retomado una particularidad devenida del caso Radilla Pacheco Vs. México, que tiene que ver que las víctimas de violaciones a derechos humanos y por ende, sus familiares tienen derecho a que sus violaciones sean conocidas y resueltas por un tribunal competente para ello ${ }^{33}$. De lo anterior se infiere la interpretación personal de que todo aquel niño en conflicto con la ley penal tiene derecho a que su causa y juicio sea seguido por una autoridad competente para ello.

\section{Principio del nemo tenetur se ipsum (el derecho a guardar silencio)}

Este principio se encuentra consagrado dentro del numeral 40.2.b.iv de la Convención, donde refiere: Que no será obligado a prestar testimonio o a declararse culpable. El principio del nemo tenetur se ha consagrado por la doctrina, en el sentido de que nadie puede declararse culpable de una conducta sin que se le haga mención a su derecho a guardar silencio y, asimismo, los efectos que su declaración (en ese momento) podrían conllevar, si es su deseo, a hacer uso o no de ese derecho. De manera particular, dentro de las especificidades que se ponderan para este principio se encuentran las particularidades que se establecen en él, y que vienen encauzadas a lo que se pondera dentro del derecho a ser escuchado como principio establecido en el numeral 12 de la CDN. Si bien, es derecho del niño a ser escuchado dentro de todo procedimiento administrativo o judicial donde se vulneren sus garantías y derechos, y que en correlación con en el principio del interés superior del niño es derecho de todo niño (s) ser escuchado (s) en relación a su edad y desarrollo, no menos cierto es que parte esencial del derecho a ser escuchado va correlacionado con el derecho a guardar silencio, si es que el niño así lo considera, tiene derecho a guardar silencio sin que esto implique que renuncia a este derecho.

\section{Derecho a interrogar o hacer que interroguen testigos de cargo/descargo}

Este principio se encuentra consagrado dentro del numeral 40.2.b.iv de la Convención, en su segunda parte donde refiere: que podrá interrogar o hacer que se interrogue a testigos de cargo y obtener la participación y el interrogatorio de testigos de descargo en condiciones de igualdad; este derecho procesal va encaminado a establecer que dentro de procedimiento deben de establecerse especificidades, con el objeto de hacer realidad la participación del niño en conflicto con la ley y su defensa; también a buscar que la información que deponen los testigos en contra del niño (acusado) pueda ser confrontada con los testigos de descargo que la defensa y el niño (acusado) presenten.

Las garantías procesales en lo presentado por el derecho a interrogar o hacer que interroguen testigos de cargo/descargo tienen como eje rector que el niño (acusado) tenga toda la información por principio de contradicción dentro de procedimiento.

\footnotetext{
${ }^{32}$ Véase: La Corte Interamericana de Derechos Humanos, Opinión Consultiva número 17, Condición jurídica y Derechos Humanos de los niños. Párrafo 120.

${ }^{33}$ Véase: Caso Radilla Pacheco Vs. México, nota 36. Párrafo 275.
} 


\section{Recurso de apelación}

Este principio se encuentra consagrado dentro del numeral 40.2.b.v de la Convención, donde refiere: Si se considerare que ha infringido, en efecto, las leyes penales, que esta decisión y toda medida impuesta a consecuencia de ella, serán sometidas a una autoridad u órgano judicial superior competente, independiente e imparcial, conforme a la ley; es un recurso efectivo que está garantizado dentro de procedimiento con el objeto de que las decisiones que se apliquen al niño (acusado) sean revisadas en segunda instancia, y también con el objeto de examinar si la decisión fue apegada a los principios y derechos establecidos en el procedimiento especializado para niños.

\section{Asistencia gratuita de un intérprete}

Este principio se encuentra consagrado dentro del numeral 40.2.b.vi de la Convención, donde refiere: Que el niño contará con la asistencia gratuita de un intérprete si no comprende o no habla el idioma utilizado; este derecho se ha consagrado dentro de las especificidades de procedimiento; al momento en que el niño no conoce o comprende el idioma en el cual se lleva a cabo el proceso, puede contar con un intérprete que garantice que el niño pueda comprender, de acuerdo a su edad, las manifestaciones que en su contra se realizan.

\section{Respeto a su privacidad}

Este principio se encuentra consagrado dentro del numeral 40.2.b.vii de la Convención, donde refiere: Que se respetará plenamente su vida privada en todas las fases del procedimiento. Este derecho, también contemplado dentro de las especificidades que se establecen en las RB, en su regla número $8.2^{34}$, deja ver que el derecho de privacidad es parte fundamental del respeto, no sólo a la dignidad humana del niño como tal, sino también, parte esencial del principio del interés superior del niño.

El derecho a la intimidad del menor, así consagrada como derecho de procedimiento, justifica una acción de no publicidad cuando el interés del menor y su derecho se encuentre en conflicto.

De lo anteriormente mencionado se puede dar cuenta de que, dentro de la estructura de la Convención, se establece una sinergia especial en cuanto a todo un sistema cimentado en principios que deben actualizarse, con la finalidad de que los Estados doten a estos adolescentes en conflicto con la ley penal de lo necesario en cuanto al respeto de los derechos propios establecidos dentro de un sistema de justicia penal juvenil.

\section{Conclusión}

La Convención es un instrumento vinculante para todos aquellos Estados que la han ratificado, de lo anterior se encamina la particularidad de que las disposiciones que emanan de este cuerpo normativo son obligatorias. De lo encontrado dentro del texto de la CDN, cuentan con un especial énfasis los numerales 37 y 40, donde se establece de primera

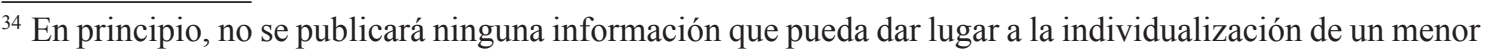
delincuente.
} 
mano qué es lo que debe acontecer con los adolescentes en conflicto con la ley penal. Es de decirse que la Convención encuadra principios básicos que son necesarios para el establecimiento de un sistema de protección a los derechos de la infancia. Lo anterior deriva en que los países signatarios de este instrumento jurídico deban adecuar sus disposiciones internas con la finalidad de ofrecer el mejor derecho para los niños y las niñas. De manera especial, es de decirse que en las temáticas de los niños, niñas y adolescentes en conflicto con la ley penal, la Convención ha diseñado un cuerpo sistemático de principios y derechos específicos que deben adecuar las naciones signatarias, con la finalidad de encaminar el mejor derecho para los niños, niñas y adolescentes en conflicto con la ley penal.

El cimiento específico que establece la Convención en cuanto a la temática de la infancia en conflicto con la ley aclara que los principios enunciados en el texto de la CDN son principios orientadores de todo un sistema que requiere, forzosamente, que las naciones lo encuadren a sus sistemas jurídicos.

A razón de lo anterior, es obligación de cada una de las naciones que han ratificado el texto de la CDN realizar cambios estructurales a sus disposiciones normativas, con la única finalidad de hacer realidad los derechos contenidos dentro de los numerales 37 y 40 de la Convención. Hoy, como ha quedado señalado, existen cuatro principios fundamentales que deben ser la guía toral de los derechos de infancia en el orbe mundial. Sin embargo, de manera particular, ha quedado también señalado que existen derechos y principios procesales específicos dentro del texto de la CDN. Los anteriores buscan de forma expresa robustecer la forma procesal de protección a los adolescentes en conflicto con la ley penal.

\section{Bibliografía}

Cillero Bruñol, Miguel (s.a), Infancia, Autonomía y Derechos: una cuestión de principios, en línea, http://www.iin.oea.org/Infancia_autonomia_derechos.pdf

Cillero Bruñol, Miguel (1999), Justicia y Derechos del Niño, número 1, El interés superior del niño en el marco de la Convención Internacional sobre los derechos del niño, Chile, UNICEF.

Corte Interamericana de Derechos Humanos (2004), caso "Instituto de Reeducación del Menor" Vs Paraguay, sentencia de 2 de septiembre de 2004 (Excepciones preliminares, Fondo, Reparaciones y Costas).

Corte Interamericana de Derechos Humanos (2003), caso Bulacio Vs Argentina, sentencia de 18 de septiembre de 2003 (Fondo, Reparaciones y Costas).

Corte Interamericana de Derechos Humanos (2002), Opinión Consultiva OC-17/2002 denominada: Condición Jurídica y Derechos Humanos del Niño.

Dworkin, Ronald (2008), La democracia posible, Principios para un nuevo debate politico, España, Paidós.

García Chavarría, Ana Belem (2012), La Convención de los derechos del niño, fascículo 8, México, Comisión Nacional de Derechos Humanos.

Herrera Zamora, Annie (2011), El impacto de la Doctrina de la Protección Integral (DPI) de los derechos de la infancia en los derechos económicos sociales y culturales (DESC) de la infancia en el DF. Tesis de Maestría. Facultad Latinoamericana en Ciencias Sociales, Sede Académica de México. 
Observación General No. 12 (2009), El derecho del niño a ser escuchado, Comité de los Derechos del Niño, CRC/GC/12/2009.

Observación General No. 4 (2003), La salud y el desarrollo de los adolescentes en el contexto de la Convención de los Derechos del Niño, Comité de los Derechos del Niño, CRC/GC/2003/4.

Observación General No. 7 (2009), Realización de los derechos del niño en la primera infancia, Comité de los Derechos del Niño, CRC/GC/2005/7.

RANGel Romero, Xochithl Guadalupe (2018), 80 preguntas sobre derechos de infancia y la justicia penal juvenil, México, editorial Flores Editor.

Zagrebelsky, Gustavo (2002), El derecho dúctil, 4ta. Edición, Madrid, Editorial Trotta. 